\title{
GÊNERO E SEXUALIDADES EM FOCO: As Discussões que Discentes do Curso de Especialização em Ensino de Biologia, Modalidade a Distância, Realizam em sua Prática Docente
}

\author{
Adelaine Ellis Carbonar dos Santos ${ }^{1}$ \\ Virginia lara de Andrade Maistro²
}

\begin{abstract}
RESUMO
A presente pesquisa tem por objetivo compreender como discentes do curso de Especialização em Ensino de Biologia, modalidade a distância, discutem a temática de gênero e sexualidades em sua prática docente. Para tanto, foi realizada a aplicação de questionário via Google Docs a discentes matriculados nos oito polos que ofertam o referido curso de Especialização de 18 a 25 de maio de 2019. Partimos da asserção de que a escola constitui-se como heteronormativa e LGBTfóbica e o percurso biológico se configura como um regulador de práticas humanas. Dessa forma, docentes da disciplina de Biologia possuem um importante papel na desconstrução de práticas com enfoque no determinismo biológico para o entendimento de gênero e sexualidades, bem como no combate a preconceitos e discriminações. Os resultados evidenciam que, em sua pluralidade, os docentes discutem tranquilamente as temáticas, tornando-se mobilizadores neste processo de abertura para tais abordagens em âmbito educacional, ainda que com a carência na formação e omissão por parte de outros docentes e da equipe pedagógica. Por fim, a maioria dos participantes concorda com a importância dos temas em âmbito escolar, utilizando das mais variadas metodologias e estratégias para refletir sobre o respeito e o enfrentamento da LGBTfobia.
\end{abstract}

Palavras-chave: gênero; sexualidades; determinismo biológico; prática docente.

GENDER AND SEXUALITY IN FOCUS: THE DISCUSSIONS THAT STUDENTS OF THE SPECIALIZATION COURSE IN BIOLOGY TEACHING, DISTANCE MODE, CARRY OUT IN THEIR TEACHING PRACTICE

\begin{abstract}
The present research aims to understand how students of the specialization course in Biology Teaching, distance mode, discuss the theme of gender and sexualities in their teaching practice. Therefore, a questionnaire was applied through Google Docs to the students enrolled in the 8 poles that offer the referred course of specialization the from May 18 to 25,2019 . We started from the assertion that the school is constituted as heteronormative and LGBTphobic and biological route shapes itself as a regulator of human practices. In this way, professors of the discipline of biology have an important role in the deconstruction of practices which focus on biological determinism for the understanding of gender and sexualities, as well as in the fight against prejudices and discriminations. The results show that, in its plurality, professors calmly discuss the themes, becoming mobilizers in this process of openness to such discussions in the educational field, even with the lack of formation and omission by other professors and pedagogical team. Finally, most of the participants agree on the importance of themes in school, using the most varied methodologies and strategies to reflection respect and coping with LGBTphobia.
\end{abstract}

Keywords: gender; sexuality; biological determinism; teaching practice.

Recebido em: 18/10/2019

Aceito em: 2/6/2020

\footnotetext{
1 Autora correspondente. Instituto Federal do Paraná - Campus Capanema. Rua Cariris, n. 750 - Bairro Santa Bárbara. Capanema/PR, Brasil. CEP 85760-000. http://lattes.cnpq.br/0138456667066620. https://orcid.org/0000-0003-0924-7328. addiecarbonar@gmail.com

2 Universidade Estadual de Londrina - UEL. Londrina/PR, Brasil.
} 


\section{INTRODUÇÃO}

Gênero e sexualidades são conceitos que perpassam todas as instâncias sociais, inclusive a escola. Sendo assim, compreender como docentes e discentes estão discutindo tais temas faz-se necessário para a compreensão da sociedade e a condução da essência de como estas abordagens estão sendo orientadas na dinâmica escolar.

Louro (2011) destaca que esses temas trazem muitas discussões em âmbito social, mas quando docentes necessitam adentrar neste diálogo em sala de aula, existe um embate muito forte e desafiador, constituindo muitas as possibilidades para o encaminhamento das discussões. Assim, a autora apresenta quatro abordagens que poderão ser desenvolvidas por educadoras e educadores, a saber: (1) compreensão de gênero e sexualidades como construções culturais; (2) reconhecimento dos marcadores simbólicos, materiais e sociais que naturalizam as diferenças e silenciam as relações de poder, a partir de um olhar do docente para os processos "históricos, políticos, econômicos, culturais"; (3) a questão da diversidade ser refletida com cuidado no que diz respeito às relações entre quem tolera e quem é tolerado e, (4) colocar as verdades universais em xeque a partir da compreensão histórica e cultural de tais conhecimentos, mediante os estudos feministas, gays, lésbicas e queer.

O contexto escolar é um espaço de processo contínuo de socialização em que os educandos têm relacionamento e convívio com sujeitos de gêneros, orientações sexuais, de mesma idade, que por vezes compartilham modos de ser, de se vestir, de ideais, opiniões e também comportamentos distintos (MELO, 2009). Ao pensarmos na Educação Básica e em jovens com mais de 11 anos de idade, visualizamos corpos em fase de produção e alterações hormonais, as quais são exteriorizadas em transformações expressivas, até mesmo comportamentais e sentimentais. E é no ambiente escolar, nos livros e na Internet, que vão procurar respostas para suas dúvidas referentes à sexualidade, principalmente quando o receio, o acanhamento e a timidez os impedem de conversar abertamente com seus familiares (FIGUEIRÓ, 2009).

Compreendemos o espaço escolar como heteronormativo. Nesse sentido, é preciso reconhecer que a escola não somente é heteronormativa, como também LGBTfóbica, resultados de discursos hegemônicos que são a base do mecanismo de gênero proposto por Butler (2013), o qual cria ficções de masculinidades e feminilidades como naturais.

Compreende-se como heterossexualidade presumida o corpo discente que tenha sua orientação sexual heterossexual, assim, a prática docente está voltada somente a esse aspecto. Essa configuração heteronormativa da escola também pode ser evidenciada quando alunos não heterossexuais são aceitos desde que se comportem, não expressando ou aparentando sua sexualidade dissidente. Aqueles que fogem desse padrão são vitimados por preconceitos e discriminações, portanto o contexto escolar não pode fechar os olhos para essas questões (BORTOLINI, 2011; JUNQUEIRA, 2017; LOURO, 2011). Em Louro (2011, p. 67) encontramos que a "homofobia circula pelos corredores e salas de aula, se insinua nos livros didáticos e aparece escancarada nos recreios e nos banheiros". Considera que devemos estimular nossos sentidos e ficarmos alertas quanto aos modos que produzem e constroem as "subordinações e hierarquias entre sujeitos e práticas sexuais, que admitem e excluem indivíduos e grupos sociais". 
Nossos olhares voltam-se, então, para essas perspectivas. O profissional docente necessita construir este olhar para os processos de exclusão e inferiorização, começando por uma desestabilização e subversão das suas próprias práticas, bem como no conhecimento e aprimoramento das suas atitudes na condição de educador e educadora. Este trabalho, portanto, tem por objetivo compreender como discentes do curso de Especialização em Ensino de Biologia, modalidade a distância, discutem a temática de gênero e sexualidades em sua prática docente.

\section{GÊNERO, SEXUALIDADES E A ESCOLA}

Como um direito universal, a escola se constitui como um espaço no qual todas as pessoas são aceitas, na medida em que seguem as normas vigentes que as controlam e as vigiam, como afirmado em Santos (2015), considerando apenas a perspectiva heteronormativa e, mesmo que a escola esteja associada à ideia de acolhimento, há determinados padrões que predominam na dinâmica escolar, ou seja, ela é disciplinadora, controladora e suas práticas cotidianas não permitem sair de seus limites.

Não é raro nos depararmos com muitas relutâncias quanto ao trabalho pedagógico dessas temáticas por sujeitos que proclamam serem defensores da moral e dos bons costumes, da conservação das normas e das tradições estabelecidas, com a crítica sendo fundamental ao debate, inferindo que discussões e reflexões de demandas quanto às sexualidades nas instituições de ensino são fundamentadas em afirmações e premissas que vão de encontro aos direitos humanos, fazendo julgamentos de que tais temas devem ser de responsabilidade apenas das famílias, numa visão religiosa, moral e ética (JUNQUEIRA, 2017). É da família a responsabilidade em educar sexualmente seus filhos e filhas, mas a escola não pode se eximir também de suas responsabilidades quanto à abertura de espaços para que os jovens possam expor suas dúvidas, anseios e angústias. Não podemos, contudo, fechar os olhos quanto ao despreparo de ambas as partes. Diante disso, os educandos passam a procurar por informações, talvez até errôneas, em fontes informais e de fácil acesso. Figueiró (2009), Maistro (2009) e Varela e Ribeiro (2017), indicam que é essencial adotarmos outra compreensão e percepção quanto aos diversos temas inseridos na Educação para as Sexualidades, quer no interior do espaço escolar ou no familiar, uma vez que é inerente aos modos como os sujeitos se concebem, atuam em sociedade, expõem seus anseios, emoções e afeições.

Diante de práticas que dizem respeito ao preconceito e discriminações que determinados docentes podem exercer durante o exercício profissional, as quais podem ser entendidas como naturais por parte das pessoas que vivenciam o espaço escolar, e assim, torna-se imprescindível que, durante a formação inicial da docência, as temáticas de gênero e sexualidades sejam postas em discussão e, posteriormente, possam debater tais temas junto a seus alunos, com vistas à promoção do respeito e combate a qualquer tipo de violência. Como afirma Santos (2015), a escola não é um mero receptáculo, constituída por práticas discursivas de menosprezo e inferiorização às sexualidades dissidentes, mas se apresenta como uma possibilidade na qual ocorrem processos de constituição mútua entre espaço escolar e prática discursiva. Compreender essa dinâmica a partir da visão de docentes possibilita a desconstrução de padrões que inferiorizam e desclassificam certas pessoas. 
Nesse sentido, Louro (2011) apresenta quatro abordagens que podem ser desenvolvidas no encaminhamento das discussões sobre gênero e sexualidades por docentes. A primeira abordagem diz respeito ao entendimento de gênero e sexualidades, considerando os temas não somente articulados, mas embaralhados entre si. Argumenta que pesquisadoras feministas buscavam compreender as especificidades de cada conceito e as articulações entre ambos. Foi então que o conceito de gênero emergiu como "construção cultural". Segundo a autora,

(...) as marcas da feminilidade são sempre diferentes de uma cultura para outra; essas marcas se transformam, são provisórias. Inscrevê-las num corpo supõe, também, lidar com as marcas distintivas do seu outro, a masculinidade. Percebe-se, então, que ao falar de gênero estamos nos referindo a feminilidades e a masculinidades (sempre no plural). A potencialidade do conceito talvez resida exatamente nesta noção, a de que se trata de uma construção cultural contínua, sempre inconclusa e relacional (LOURO, 2011, p. 63-64).

Sendo o gênero entendido como construção cultural, existe uma dificuldade de compreender também a sexualidade como um processo de construção, associando-a "à natureza ou à Biologia". Este determinismo biológico tem sido encontrado em muitos estudos relacionados à genética e neurociências que, por meio das discussões apresentadas, identificam e justificam os diferentes comportamentos e cognições entre homens e mulheres levando em consideração somente as questões genéticas e neurofuncionais, excluindo qualquer outro elemento, como exemplo os aspectos culturais. Essa ideia essencialista tem conquistado espaço no seio social por meio das mídias que a reproduzem e contribuem para o convencimento, utilizando-se do determinismo biológico para explicar todos os fenômenos, incluindo questões de gênero e sexualidades, reproduzindo o padrão daqueles indivíduos tidos como "anormais", "diferentes", "fora dos padrões" (ANDRADE, 2011).

Esse processo de diferenciação, segundo Louro (2011), acontece mediante marcadores simbólicos, materiais e sociais, os quais disfarçam a construção desse processo, não somente naturalizando a diferença, mas também silenciando as relações de poder que estão imbricadas. Assim sendo, a diferença não é natural, é determinada pelos processos discursivos e culturais e é imposta. Dessa forma, é imprescindível o reconhecimento desses marcadores por parte dos docentes, evitando essa naturalização e considerando os processos históricos, políticos, econômicos e culturais que estabeleceram a identidade suposta, ou seja, a referencial. O terceiro ponto que a autora aborda é sobre a diversidade cultural, mais especificamente o termo "multiculturalismo", o qual pode ser uma ferramenta para a compreensão histórica sobre a diferença. Há a ideia de que existe uma coexistência harmoniosa da diversidade a partir da tolerância, entretanto a tolerância torna-se um elemento hierárquico na medida em que se coloca a pessoa que tolera em evidência, isto é, superior. Finalmente, Louro (2011) evidencia a quarta abordagem que os temas de gênero e sexualidades podem ser desenvolvidos, referindo-se aos campos inter ou multidisciplinares para a construção do conhecimento, ou seja, os Estudos Feministas, Estudos Gays, Estudos Lésbicas e os Estudos Queer. Estes estudos nos mostram que os temas de gênero e sexualidades são constituídos por relações 
históricas e culturais, sendo necessário colocar em questão nossas certezas universais, contribuindo assim, não somente no campo da educação, “(...) mas a cultura, as instituições, o poder, as formas de aprender e de estar no mundo" (LOURO, 2011, p. 69).

As pesquisas sobre gênero e suas reflexões começaram a emergir graças às pesquisadoras feministas Scott (1995) e Butler (2013). Segundo Scott (1995), gênero é o elemento constituidor de relações sociais segundo as distinções sexuais entre homens e mulheres, além de ser o primeiro elemento a dar sentido às relações de poder, rejeitando explicações biológicas, indicando somente construções culturais. É uma construção cultural na qual se origina uma hierarquia entre homens e mulheres, em uma lógica generificada de poder. Para Butler (2013), o gênero pode ser entendido como um mecanismo que naturaliza as feminilidades e masculinidades mediante uma oposição binária, a partir da heteronormatividade, isto é, a heterossexualidade como norma. Esse mecanismo funciona com o auxílio de discursos culturais hegemônicos denominados de discurso jurídico e discurso médico-biológico, limitam as expressões possíveis do gênero, baseados na bipolaridade masculino e feminino, homem e mulher, macho e fêmea. Sendo assim, as práticas discursivas naturalizam aquilo que é entendido como feminilidades e masculinidades, ou seja, o que é entendido para "ser homem" e "ser mulher" e sustentam as "identidades de gênero inteligíveis", que mantêm coerência entre sexo, gênero e desejo; as "identidades de gênero ininteligíveis ou descontínuas", que por sua vez não mantêm tal coerência, não se conformando com as normas culturais de gênero (BUTLER, 2013).

O discurso biológico constitui-se como um regulador de práticas humanas, na medida em que o gênero é "(...) uma categoria social imposta sobre um corpo sexuado" (SCOTT, 1995, p. 75). Desta forma, professores de Biologia possuem um importante papel na desconstrução de práticas biologizantes para a compreensão do gênero e das sexualidades e para o combate de preconceitos e discriminações, em especial a LGBTfobia.

As temáticas de gênero e sexualidades são consideradas um tabu, originando uma dificuldade em se discutir tais temas em sala de aula, tornando certos discentes reféns de piadas, agressões e discriminações, evidenciando uma cultura LGBTfóbica constituinte na dinâmica escolar (CAVALEIRO, 2009). Nesse sentido, se silenciamos no espaço escolar as discussões sobre os mais diversos temas que envolvem a sexualidade, preconceitos e discriminações, eles passam a ser naturalizados.

Para Felipe e Bello (2009), é preciso tratar questões referentes à orientação sexual desviante do padrão heteronormativo como algo corriqueiro na escola, não somente discutir sobre essas questões apenas quando o "problema" vem à tona. Os docentes não buscam o conhecimento da temática em si, mas tentam "corrigir o problema". Compreender as questões de identidade de gênero e orientação sexual desviantes da heteronormatividade como um problema a ser corrigido é colocar as sexualidades dissidentes como inferiores em relação à heterossexualidade, originando aquilo que Borrillo (2010) determina como uma hierarquia entre as sexualidades, estabelecidas, iniciando com as relações de poder entre "normal" e "anormal". 
A sexualidade faz parte de nossas vidas e por sermos seres sexuais as concepções sobre gênero e sexualidades serão refletidas nas diferentes instâncias sociais, sendo, por vezes, carregadas de preconceitos e tabus. Dessa forma, compreender como discentes do curso de Especialização em ensino de Biologia discutem a temática de gênero e sexualidade em sua prática docente pode contribuir no entendimento de como essas questões estão sendo abordadas em âmbito escolar, bem como quais as estratégias utilizadas pelos docentes no que respeita à temática.

\section{METODOLOGIA}

Como procedimento metodológico foi realizada a pesquisa de campo para dar melhor inteligibilidade ao fenômeno, buscando a informação diretamente com o objeto pesquisado (GONSALVES, 2001). Assim, esta pesquisa é do tipo qualiquantitativa, de forma que a abordagem quantitativa apreende a abordagem concreta dos fenômenos e a qualitativa aprofunda-se nos significados das ações e relações humanas (MINAYO, 2002).

Para a obtenção dos dados foi aplicado um questionário via Google Docs a docentes que atuam ou já atuaram na rede de ensino, matriculados nos oito polos que ofertam o referido curso de Especialização em uma universidade pública do Paraná. Os polos são pertencentes às cidades desse mesmo Estado, a saber: Apucarana, Assaí, Bandeirantes, Ivaiporã, Laranjeiras do Sul, Londrina, Pato Branco e Prudentópolis. 0 contato com os discentes do curso de Especialização deu-se a partir dos tutores de cada polo.

O questionário é composto por 18 perguntas, das quais 3 questões são abertas e 15 fechadas, que ficou disponível para preenchimento on-line de 18 a 25 de maio de 2019. Após a obtenção, os dados foram inseridos no banco de dados a partir do software LibreOffice Calc; posteriormente sendo sistematizados e categorizados seguindo a análise de conteúdo do discurso de Bardin (1977) e que deram origem a gráficos, os quais foram analisados e discutidos. Pelo fato de tal questionário ser aplicado via Google Docs, sem o contato direto com os participantes, bem como se configurar como um levantamento de dados que não compromete a identificação dos sujeitos, este trabalho não passou pelo Comitê de Ética em Pesquisa.

\section{RESULTADOS E DISCUSSÃO}

Os dados obtidos a partir da aplicação do questionário evidenciaram que seis professores estão matriculados no polo de Londrina, seis no polo de Bandeirantes, cinco no polo de Apucarana, seis no polo de Prudentópolis e três no polo de Assaí. Não obtivemos retorno dos polos de Ivaiporã, Laranjeiras do Sul e Pato Branco. O Gráfico 1 evidencia as porcentagens da participação por polo. 
Gráfico 1 - Quantidade de discentes participantes da pesquisa por polo .

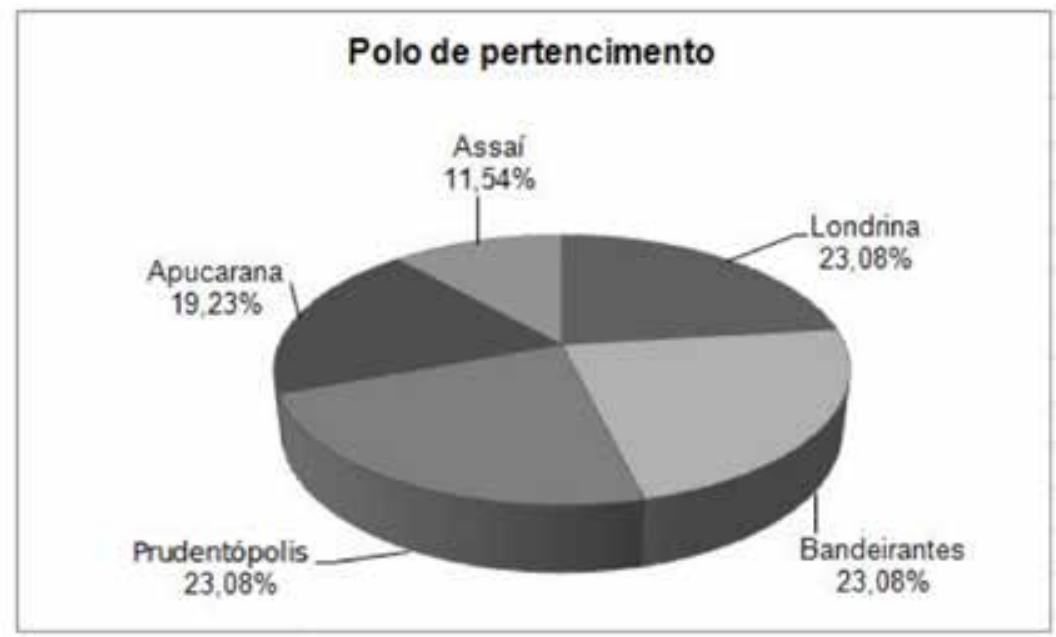

Fonte: Elaborado pelas autoras.

Com relação à cidade de residência dos participantes no Paraná tivemos: 1 de Andirá, 2 de Arapongas, 1 de Assaí, 1 de Castro, 2 de Cornélio Procópio, 2 de Curitiba, 7 de Londrina, 1 de Paraíso do Norte e 1 de Prudentópolis; e além do Paraná, tivemos 1 do Distrito Federal, 5 do Estado de São Paulo: 1 de Garça, 1 de Ourinhos, 1 de Porangaba, 1 de São Caetano do Sul, 1 da capital e 2 não responderam. Os dados categorizados a partir das mesorregiões do Estado do Paraná (IBGE, 2010), ${ }^{3}$ temos as seguintes porcentagens: Norte Central (34,62\%); Norte Pioneiro (15,38\%); Metropolitana (7,69\%); Noroeste $(3,85 \%)$; Sudeste (3,85\%); Centro-Oeste (3,85\%). Ainda, $19,23 \%$ dos participantes residem em cidades do Estado de São Paulo; 3,85\% no Distrito Federal e 7,69\% não responderam.

A partir dos resultados obtidos por meio da aplicação do questionário, evidenciamos que o curso EaD possibilitou que a maioria dos profissionais graduados não residentes na cidade da instituição de ensino que disponibilizava o curso pudessem aprimorar seus conhecimentos, enriquecendo suas práticas e experienciando outros caminhos profissionais, visto que não somente licenciados em Ciências Biológicas realizaram o curso. Sendo assim, a EaD promove a troca de saberes, principalmente entre aqueles com menor poder aquisitivo ou que moram distante de áreas que se configuram como polos universitários, propiciando o vínculo afetivo e profissional entre alunos e demais profissionais, mediante contatos interpessoais e ferramentas voltadas à educação, independentemente do local, "o acesso ao conhecimento e às informações chegam aos mais diferentes locais desse nosso país de dimensões continentais, assim a aprendizagem se torna significativa através da interação assertiva" (LOBO, 2011, p. 108).

Concordamos com Gottardi $(2015$, p. 1) quando afirma que a EaD "oportuniza aquisição de conhecimentos e desenvolve competências e saberes para o enfrentamento de situações profissionais cada vez mais complexas e desafiadoras". E é nesta conjuntura que podemos refletir sobre a participação da EaD no fomento das discussões

3 Mesorregiões geográficas do Estado do Paraná. Disponível em: http://www.ipardes.gov.br/pdf/mapas/base_fisica/ mesorregioes_geograficas_base_2010.jpg. Acesso em: 25 maio 2019. 
de gênero e sexualidades, em especial na formação continuada de professores, visto que essas discussões são por vezes omitidas em muitas grades curriculares de cursos de Graduação. Conforme Rizza, Ribeiro e Mota (2018), disciplinas voltadas a gênero e sexualidades são ofertadas em sua maioria nos cursos de Licenciatura, embora a discussão do tema em âmbito escolar não esteja presente em todas.

Quando falamos em gênero e sexualidades temos de levar em consideração o contexto das pessoas que estão inseridas no processo, seja ele educacional ou não, pois é nesta conjuntura (histórico social, político, religioso, cultural, etc.), que as discussões sobre o assunto serão orientadas. Perceber qual o local de fala que os participantes desta pesquisa ocupam, a partir do seu perfil, é propiciar uma maior reflexão sobre o objeto de estudo. Assim, o gráfico a seguir (Gráfico 2 ) evidencia a prática religiosa dos discentes participantes.

Gráfico 2 - Prática religiosa dos participantes

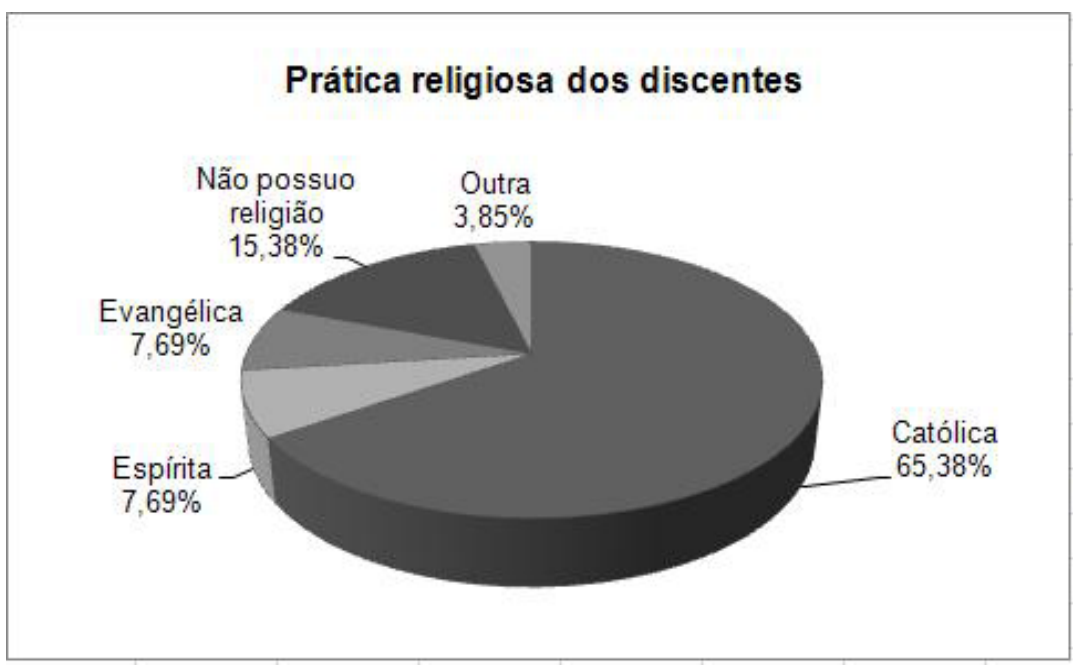

Fonte: Elaborado pelas autoras.

Um dos contextos que determina a orientação das discussões sobre a temática é o religioso. Não temos a pretensão de afirmar que pessoas são preconceituosas por professar uma religião, mas as instituições religiosas contribuem para o fortalecimento da LGBTfobia e sexismo. Por vezes, elas introduzem ideias que são reproduzidas na vivência escolar, influenciando profissionais docentes e discentes a praticarem atos LGBTfóbicos contra as pessoas que não seguem as normas heterossexuais (SANTOS, 2015). As concepções que docentes possuem influenciam o trabalho sobre as sexualidades. Para tanto, uma abordagem religiosa pode oferecer resultados positivos ou negativos, ao passo que somente abordagens médicas ou biológicas limitam a sua compreensão (RODRIGUES; SALLES, 2011).

Santos (2015) compreende a religião como reguladora de práticas sociais, com o discurso teológico-monoteísta constituindo um dos discursos que alimentam o mecanismo de gênero discutido por Butler (2013) e que também promove a LGBTfobia, pois, na visão do cristianismo, a sexualidade se transforma em via pecadora que levava à desonra, condenando atos não heterossexuais como atos de oposição à natureza (CATONNÉ, 2001). 
Isso posto, pesquisamos, junto aos participantes, sobre o número de escolas em que atuam, sua formação profissional, tempo de serviço e carga horária semanal. As respostas obtidas evidenciam que a maioria: (a) atua em escola pública, às vezes mais de uma escola por dia, (b) com carga horária semanal entre 20 e 40 horas/aula, e (c) tempo de serviço (prática docente) entre 1 e 5 anos. Com relação à formação após a Graduação: 9 possuem somente Graduação, 10 têm Especialização e 7 têm Mestrado. Quanto ao curso superior: 14 são formados em Ciências Biológicas, 1 em Zootecnia, 1 em Enfermagem, 1 em Pedagogia e 1 em Agronomia e 8 não informaram o curso de Graduação.

O gráfico a seguir evidencia a formação inicial dos discentes matriculados no curso de Especialização em Ensino de Biologia (UEL) em porcentagem (\%):

\section{Gráfico 3 - Formação inicial dos discentes participantes}

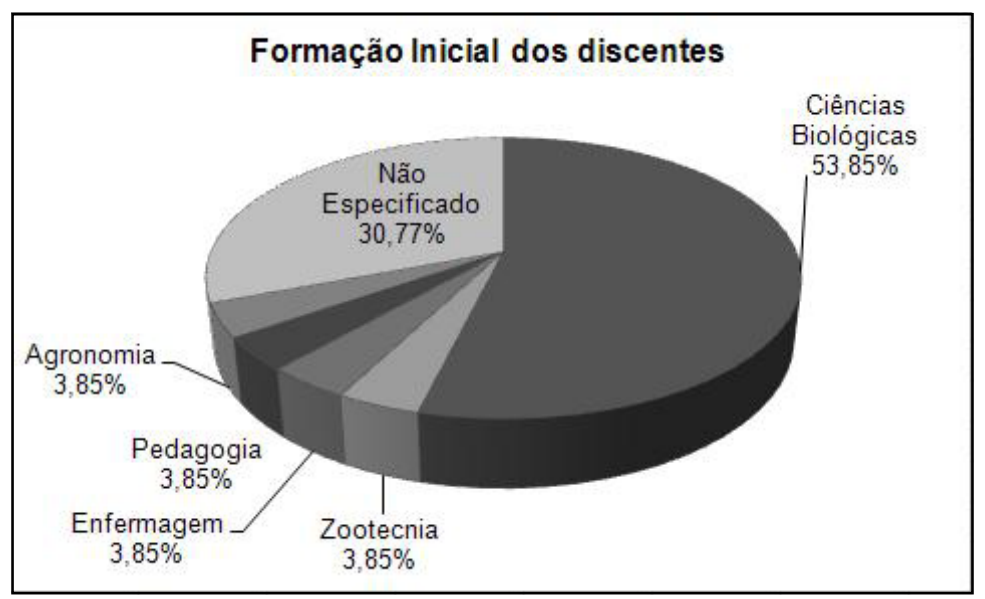

Fonte: Elaborado pelas autoras.

Com o perfil dos discentes evidenciado, os gráficos posteriores correspondem à prática docente relacionada às temáticas de gênero e sexualidades. Assim, quando perguntados sobre os motivos de se evitar discutir a temática em sala de aula, temos os seguintes dados (Gráfico 4):

Gráfico 4 - Motivos que levam a evitar discutir a temática em sala de aula

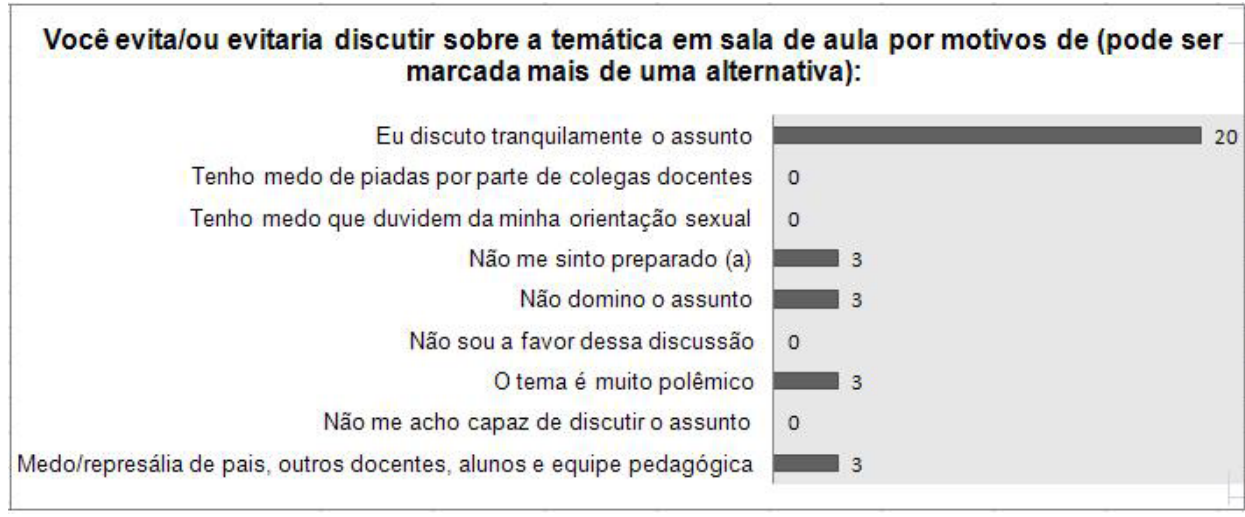

Fonte: Elaborado pelas autoras.

Evidenciamos que os participantes não se opõem às discussões, não têm medo de piadas e nem de que seus pares duvidem da sua orientação sexual, mas que evitariam a discussão de gênero e sexualidades por motivos de: o tema ser muito polêmico (3); 
por não se sentirem preparados (3); por não dominarem o assunto (3); bem como por medo/represália de pais, outros docentes, alunos e equipe pedagógica (3). Destaca-se que, nenhum assinalou a opção "não me acho capaz de discutir o assunto".

Uma associação entre dados importante de ser ressaltada nessa discussão foi que, aqueles que marcaram a opção "não domino o assunto" e "o tema é muito polêmico", também assinalaram a afirmativa "nunca participei" de eventos (formação pedagógica, palestras, congressos, simpósios, oficinas, etc.) voltados à temática, como evidencia o Gráfico 5.

Gráfico 5 - Participação em eventos voltados à temática

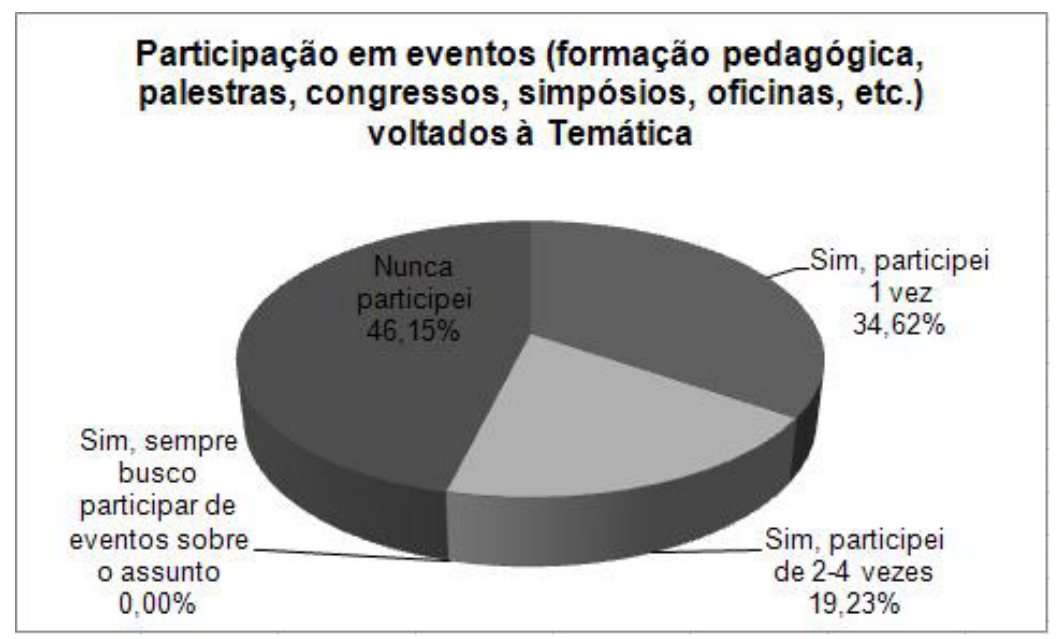

Fonte: Elaborado pelas autoras.

Evidencia-se neste gráfico que a maioria nunca participou de qualquer formação continuada (46,15\%), e $34,62 \%$ apenas uma vez, o que consideramos pouquíssimo, considerando que para discutir e refletir sobre os mais diversos temas que abarcam as sexualidades e gênero são necessárias: formação para tal por meio de leituras, participação em congressos, simpósios, oficinas e outros que permitam fazer uma releitura da temática sem preconceitos, tabus, ideologias e sem fundamentalismos religiosos, apesar de não ser garantia de promover uma formação efetiva.

Gráfico 6 - Tempo que os discentes discutem a temática em sala de aula

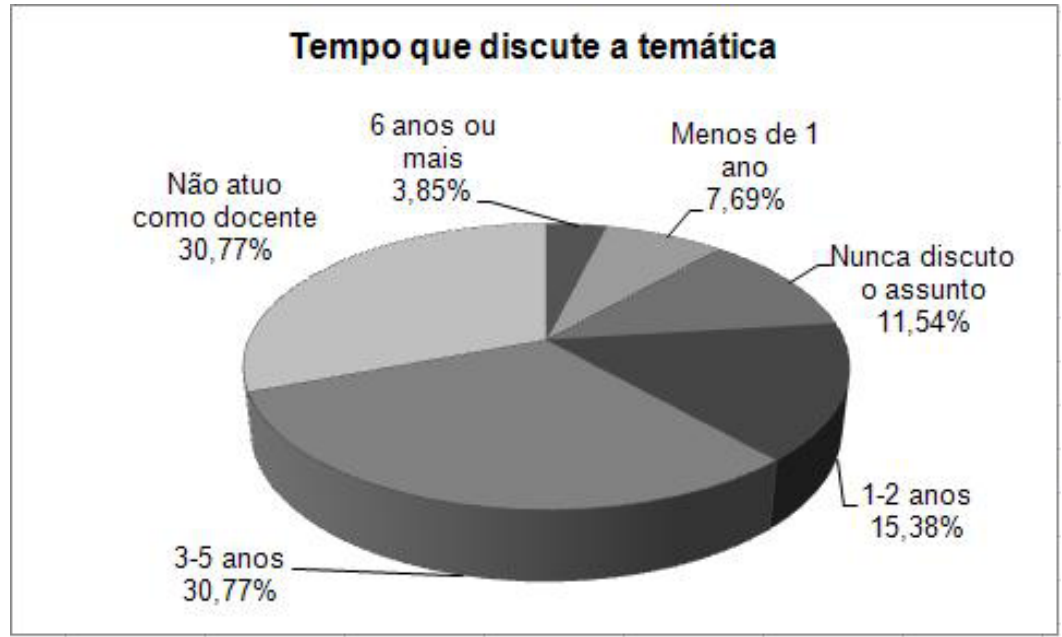

Fonte: Elaborado pelas autoras. 
Mesmo considerando a escola como um espaço democrático, ainda estamos andando muito lentamente quanto ao levar para dentro dos muros escolares discussões sobre o enfrentamento da diversidade que se encontra nesses espaços e mesmo que seja lento o passo, ele está acontecendo, o que é muito importante, apesar de ser insuficiente.

Gráfico 7 - Intensidade do preparo para abordar a temática em sala de aula

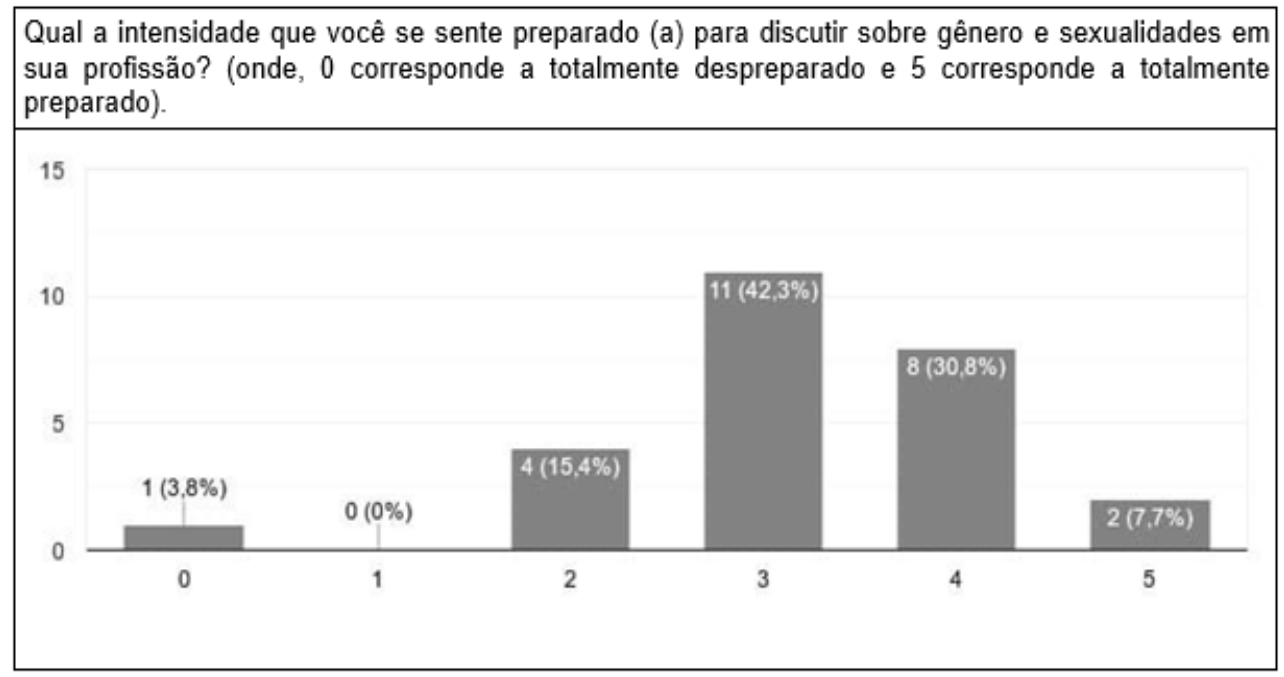

Fonte: Elaborado pelas autoras.

Quando perguntados sobre a intensidade do preparo para abordagem do tema, $80,8 \%$ dos participantes assinalaram entre 3 e 5, em que 5 corresponde a totalmente preparado. Isso está diretamente relacionado aos dados do Gráfico 4, em que 18 participantes afirmam discutir tranquilamente o assunto. Desses, somente 2 assinalaram a opção 5, afirmando estarem totalmente preparados.

Os professores têm dificuldades em trabalhar a temática devido a uma cristalização daquilo que é considerado padrão, influenciando numa prática voltada à heteronormatividade, resultado de um contexto sociocultural em que estão imersos, desenvolvendo uma prática simplista e reducionista do tema, que pode levar a uma invisibilidade das homossexualidades, a partir do silenciamento, uma vez que as diretrizes curriculares produzem uma homofobia institucional quando visibiliza somente modelos heteronormativos. As aulas e livros didáticos de Biologia estão repletos de aspectos heteronormativos (forma funcional e reprodutiva), de visões higienistas das sexualidades, restringindo o tema a aspectos conceituais básicos, voltados, sobretudo, a aspectos morfoanatômicos do corpo humano, desconsiderando qualquer outra possibilidade de práticas (SANTOS, 2015; MOKWA, GONINI; RIBEIRO, 2009; MOREIRA, 2012).

Nesse sentido, consideramos o que pode contribuir para a construção do conhecimento relacionado a gênero e sexualidades: é a realização de projetos, de possibilidades de espaços para a formação pedagógica continuada voltados à temática, promovidos pela própria escola. Segundo o questionário, 30,77\% dos discentes participantes afirmam que suas escolas não realizam ou não realizaram tais propostas de formação ao corpo docente. Isso vai de encontro às considerações de Louro (2013) e Batista (2008), 
quando argumentam que as sexualidades não são discutidas naturalmente pela escola, dando a ilusão de que não trabalhando a temática os "impasses" não farão parte da vivência escolar, compreendendo a negação como resolução do "problema".

Essas considerações podem ser constatadas no Gráfico 8, em que 7,69\% dos discentes participantes responderam "prefiro me omitir do assunto"; 23,08\% afirmam que o melhor meio para iniciar uma discussão sobre o tema é quando está havendo uma prática LGBTfóbica e $69,23 \%$ dos participantes da pesquisa acreditam que criar um tópico na ementa da disciplina seja a melhor opção para se discutir gênero e sexualidades.

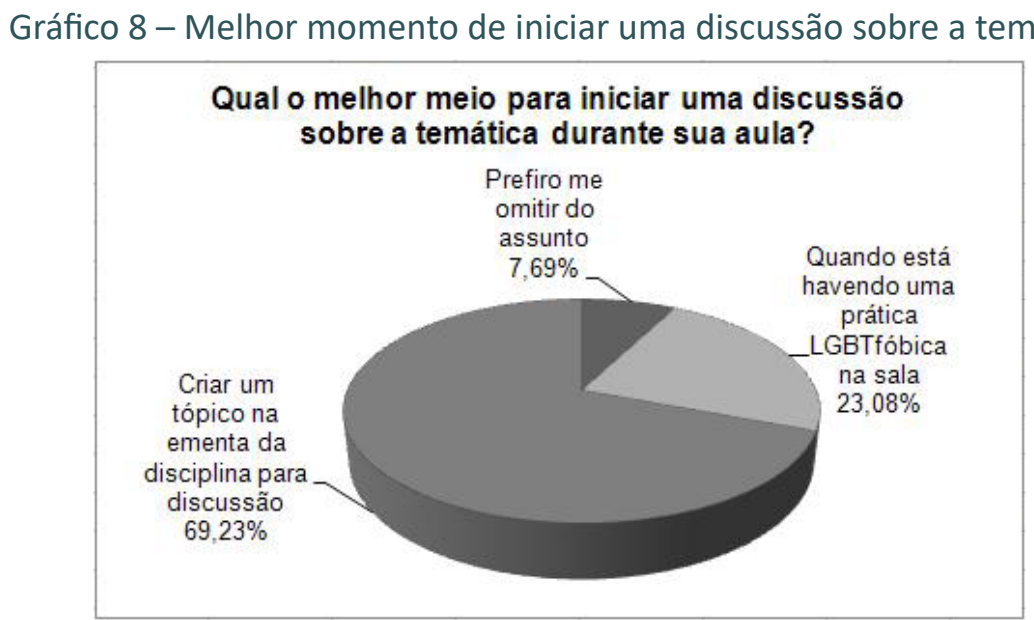

Fonte: Elaborado pelas autoras.

A omissão, para Santos (2015, p. 148), não pode ser compreendida como mera falta de informação ou de carga horária insuficiente, mas como uma possível LGBTfobia passiva “(...) decorrente da falta de interesse em conjunto, muitas vezes, com o próprio preconceito", às vezes velado. Vale destacar que um dos discentes que assinalou a opção "prefiro me omitir", também assinalou "nunca participei de eventos" e informou que não acredita ser importante as discussões de gênero e sexualidades na escola, pois, segundo o mesmo, "é uma situação particular de cada pessoa" (Questionário № 10). O mesmo participante da pesquisa argumenta que em casos de LGBTfobia em sua aula, encaminharia os envolvidos para a equipe pedagógica, mesmo informando a inexistência do apoio da mesma para discussões sobre o tema, assinalando a opção 0, que correspondia a nenhum apoio (Gráfico 9).

Gráfico 9 - Intensidade do apoio da equipe pedagógica para discussões sobre gênero e sexualidades na escola

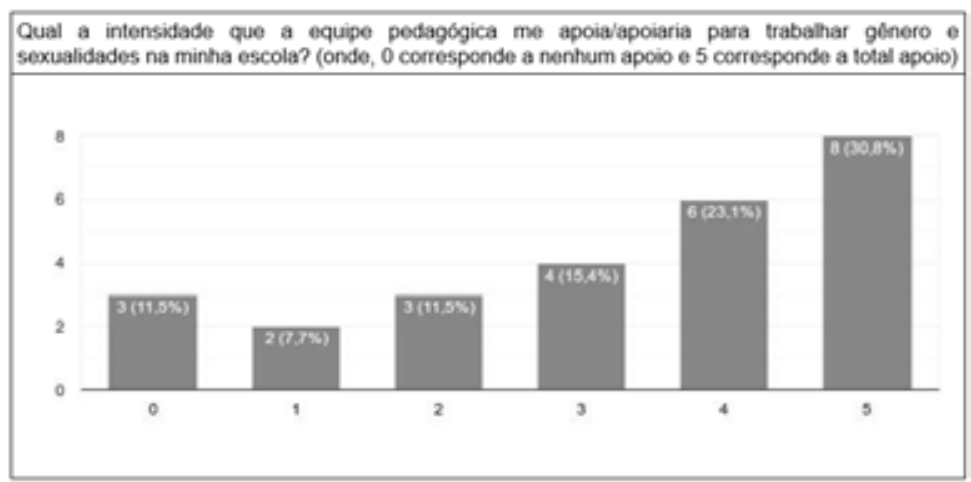

Fonte: Elaborado pelas autoras. 
Esse gráfico confirma que existe uma certa omissão e despreparo da equipe pedagógica na mediação de conflitos que envolvam discentes não heterossexuais. E quando existem lacunas, este "não dizer", esta ausência de ação, a equipe pedagógica demonstra uma inércia quanto às práticas não heteronormativas quando são escancaradas no contexto escolar, contribuindo para os silenciamentos, para a inexistência de projetos para a formação continuada sobre gênero e sexualidades, o que poderia levar os docentes a se posicionarem contra qualquer preconceito, tabus diante das diversidades postas no cotidiano escolar.

Sendo assim, além de compreender que as instituições educacionais são generificadas e LGBTfóbicas, também é imprescindível reconhecer a necessidade destas discussões para uma desestabilização de padrões preconceituosos e discriminatórios em âmbito educacional. Assim, ao serem perguntados sobre a importância destas discussões, as respostas não são unânimes entre os participantes, destacando-se que dois afirmam a não importância da discussão em sala de aula, destacando que "não concordo, pois receio que possamos estar influenciando. Prefiro não opinar" (Questionário № 6). Por outro lado, 24 acreditam na importância do tema. A seguir, algumas respostas dos participantes:

Sim, devemos abordar temas assim na escola, já que ela é um local onde trocas de informações são necessárias, visto que assuntos assim não são discutidos nas famílias na maioria das vezes, então a escola tem um papel fundamental para construção de ideias a respeito do tema (Questionário № 14).

Sim, visto que somos uma sociedade diversa. Dessa forma, lidamos com múltiplos gêneros e sexualidades, sendo interessante a professor de ciências/biologia tratar a temática com respeito e maiores informações, diminuindo o preconceito e "medo" de se tratar do assunto (Questionário № 11).

Sim, pois é um tema que precisa ser discutido em sala de aula, para que os alunos tenham um conhecimento científico e não apenas senso comum, pois é onde inicia o preconceito e a discriminação (a falta de conhecimento) (Questionário № 17).

Acho importante sim, pois muitas vezes os pais não abordam esses temas em casa. Com esse momento na escola, os alunos podem compreender os diferentes conceitos relacionados ao gênero e à sexualidade e, consequentemente, entender meIhor e respeitar seus amigos, familiares e a si próprios. Mais importante do que a abordagem do tema é a preparação do profissional que estará transmitindo essas informações (Questionário № 25).

Entre os 24 que acreditam na importância de discutir gênero e sexualidades na escola, entretanto, 4 afirmam concordar, porém com ressalvas, como no caso dos discursos a seguir:

Sim, entretanto acredito que deve ser respeitada a individualidade de cada um, assim como o tempo de cada um. Muitos jovens têm problematizado o assunto, pois este tem sido abordado excessivamente, é como se fosse algo tão falado que todo mundo quer experimentar. Devemos deixar as coisas seguirem seu percurso normal e tratar com normalidade o que fugir disso (Questionário № 1). 
Sim, respeitando a faixa etária, é de suma importância, já que a maioria dos alunos não conversa sobre sexualidade com os pais, então os mesmos precisam de orientação (Questionário № 7).

Acho importante só para os mais velhos, a temática de gênero (Questionário № 3).

Sim. Mas preciso me preparar para o tema (Questionário № 4).

Um ponto importante de ser refletido a partir das respostas é a ausência destas discussões em âmbito familiar, destacando também que, junto as discussões na escola, o profissional deve estar também preparado para os desafios que irá enfrentar na prática docente. Outra questão diz respeito à faixa etária para abordar o tema, devendo ser respeitada, assim como a individualidade de cada um.

A ausência e silenciamento dos temas que envolvem as sexualidades no seio da família podem ser refletidos, quando compreende a instituição familiar como LGBTfóbica, em que a casa, considerada local de acolhimento, torna-se sinônimo de sofrimento e dor para pessoas com gênero e sexualidades dissidentes. Essas discussões na família possibilitam uma formação voltada à promoção do respeito, pois trabalhar com o assunto desde a infância diminui as chances de a criança se tornar intolerante quando adulta. Sendo assim, as discussões sobre o tema em âmbito familiar estão diretamente relacionadas ao rompimento de preconceitos nas próprias relações intrafamiliares (GUERRA; ROCHA, 2013; SANTOS, 2015).

Não é, contudo, o que constatamos nas respostas obtidas. Ao contrário, esta ausência de discussões em âmbito familiar pode ser compreendida naquilo que Felipe e Bello (2009) argumentam ser uma "infância heterossexualizada", utilizando da metáfora das órbitas, sendo na fase da infância que estamos mais próximos à matriz heterossexual. Assim sendo, a faixa etária de cada indivíduo deve sim ser respeitada, entretanto não se pode afastar o indivíduo do assunto, uma vez que a própria sexualidade faz parte da constituição do seu ser.

Com relação à pergunta "Em sua prática docente de que forma você discute/discutiria gênero e sexualidades?", muitas metodologias foram descritas pelos participantes. A exibição de vídeos, rodas de conversas, notícias reais de situações que ocorrem na sociedade trazendo para a realidade do aluno, exposição dialogada de artigos científicos e atribuição dos conhecimentos prévios dos envolvidos estão entre as ferramentas mais utilizadas para fomentar a discussão.

A seguir, alguns discursos de como os profissionais estimulam as discussões sobre gênero e sexualidades:

Trabalho em equipe, vídeos, teatro, artigos cientificos, casos reais que acontecem a todo momento na sociedade (Questionário № 14).

Normalmente o tema aparece de forma natural e com exemplos que eles mesmos trazem, assim eu aproveito o que eles têm de conhecimento e sem falar diretamente nas palavras "gênero e sexualidade" tento fazê-los pensar e refletir sobre o assunto tentando desconstruir conceitos já formados. Um dos temas é, por exemplo, a disparidade entre salários de mulheres e homens e trabalhos em que encontramos mais homens do que mulheres. Discutimos como a sociedade valoriza o trabalho e como as oportunidades são diferentes para ambos os sexos, assim como as responsabilidades que a sociedade impõe (8o ano). Já trabalhei com Ed. Infantil e sempre 
ocorrem discussões sobre brinquedos de meninas/meninos e cores de meninas/meninos, nessa situação intervenho imediatamente dizendo que cores são para todos, assim como os brinquedos, tanto meninas como meninos podem utilizar/brincar com o que desejarem. A metodologia em ambas as situações é a discussão do tema pelo grande grupo (Questionário № 17).

Discuto com meus alunos muitas vezes formando rodas de conversas, utilizando slides, notícias recentes para que eles tenham a percepção de como o assunto é abordado em nossa sociedade e como devemos lidar com o tema. Gosto muito de levar alguns trechos dos direitos humanos para debatermos nesses momentos (Questionário № 24).

Como dito na resposta anterior, a questão é sempre levantada dentro do ensino do sistema reprodutor. Os tópicos normalmente abordados são orientação sexual (heterossexualidade, homossexualidade, bissexualidade, pansexualidade), cisgêneros e transgêneros. Sempre tento apresentar o assunto da maneira mais natural possível, apesar de que, como respondido em uma das perguntas acima, ter dificuldades de lidar com alguns membros da direção, que, por motivos religiosos em especial, não concordam muito com a discussão do assunto e com certas visões que os alunos trazem de casa. Também acredito que meu conhecimento sobre o assunto não é muito profundo, então tento complementar o conteúdo com a apresentação de vídeos e documentários (Questionário № 20).

Como podemos perceber, não existe um protocolo de como abordar o tema em sala de aula, ficando a critério do profissional escolher qual a metodologia que mais se encaixa para seu público. O que vale aqui é não se omitir ou silenciar, visto que as discussões sobre a temática são respaldadas pela legislação, embora muitas vezes de forma não efetiva, seja pelo desconhecimento, falta de interesse ou despreparo profissional.

Mesmo com os desafios, despreparo profissional e tentativas de silenciamentos, os casos que envolvem preconceitos e discriminações fazem parte não somente do cotidiano escolar, mas da vivência social de todas as pessoas envolvidas no processo. Assim, ao questionar quanto às estratégias utilizadas em situações de LGBTfobia pelos participantes, durante sua prática docente, nos proporciona um panorama das atitudes tomadas pelos participantes, ao passo que, para Dinis e Cavalcanti (2008), são as estratégias políticas que colocam em xeque o sistema normatizador de identidades sexuais e de gênero.

A seguir estão as respostas de alguns questionários:

Conversaria com toda a turma sobre a relevância do respeito, dos perigos do preconceito, e buscaria algum meio de sensibilizá-los (Questionário № 22).

Conversaria com a turma sobre o assunto de maneira geral. Sem apontar os alunos envolvidos. Posteriormente pediria para conversar com a vítima e com os outros alunos separadamente, em conjunto com a pedagoga e também os pais (Questionário № 8).

Transformar o momento em uma conversa com toda a turma, para identificar o que eles sabem sobre o tema, quais conceitos apresentam de forma errada e, principalmente, explicar um pouco sobre as questões de gênero e sexualidade para que os alunos percebam que não há certo e errado, há uma grande diversidade que precisa ser respeitada, acima de tudo (Questionário № 25). 
Procuraria vídeos para mostrar que ninguém é igual a ninguém, a escolha é individual e levaria o caso à coordenação pedagógica que acredito ser a responsável para resolver isso (Questionário № 3).

Encaminharia à coordenação pedagógica (Questionário № 10).

A partir das respostas, podemos evidenciar três eixos de estratégias, sendo eles: (1) conversa e sensibilização; (2) abordagem do assunto; (3) encaminhamento à coordenação pedagógica. Assim, num primeiro momento os discentes participantes informam que em casos de LGBTfobia uma conversa com vistas à sensibilização perante a turma se faz pertinente e, por vezes, suficiente. Outra estratégia apontada seria aproveitar a situação e discutir o tema, promovendo o respeito e a diversidade. Por fim, a estratégia de encaminhar para a equipe pedagógica, podendo estar vinculada ao comparecimento dos pais/responsáveis pelos alunos à escola.

Essa última estratégia, contudo, está na contramão do que foi destacado nas respostas anteriores, uma vez que, de acordo com Santos (2015), o apoio por parte da equipe pedagógica não é efetivo, em conjunto com a omissão e despreparo dessa equipe na mediação de conflitos.

\section{CONSIDERAÇÕES FINAIS}

Este trabalho teve por objetivo compreender como discentes do curso de Especialização em Ensino de Biologia, modalidade a distância, discutem a temática de gênero e sexualidades em sua prática profissional. Pela modalidade do curso, possibilitou-se que profissionais de outros lugares do país pudessem participar e enriquecer seus conhecimentos. O contato para o preenchimento do questionário, entretanto, foi dificultado, não somente pela ausência de engajamento de alguns tutores do curso no encaminhamento do mesmo para seus respectivos polos, mas também pela pouca adesão entre os participantes, possivelmente devido à temática.

A escola, em seu exercício social, como um espaço democrático, deve ensejar discussões sociais e possibilitar espaços para que o desenvolvimento do pensamento crítico aconteça, trazendo informações, contextualizando-as e, desta maneira, contribuir para que as mais diversas violências quanto ao gênero e orientações sexuais não sejam naturalizadas, desmistificando e oportunizando a construção de valores e atitudes saudáveis.

Constatar que do total de participantes da pesquisa, 20 discutem tranquilamente a temática em sua prática, nos faz acreditar em um movimento de abertura para tais discussões em âmbito educacional, projetando no profissional docente essa mobilização. É notável, contudo, a falta de preparo de uns e omissão de outros para o estabelecimento das discussões de gênero e sexualidades em sala de aula. Também, a falta de projetos e eventos escolares sobre o tema repercute diretamente na dinâmica escolar e na prática cotidiana, uma vez que não é proporcionada pela escola uma formação continuada ao seu corpo docente. Isso denuncia também uma omissão por parte da equipe pedagógica de algumas escolas, ausentando-se dessas discussões, sobretudo no apoio a professores que discutem gênero e sexualidades. 
Por fim, a maioria dos participantes concorda com a importância das discussões em âmbito escolar, utilizando das mais variadas metodologias para a promoção do respeito e realizando estratégias para o enfrentamento da LGBTfobia em sua profissão. Desse modo, esta pesquisa proporcionou uma compreensão das questões de gênero e sexualidades, bem como para o Ensino de Biologia e sua relação com a prática profissional, não esgotando as discussões sobre o tema; ao contrário, possibilitando uma abertura para novos questionamentos e análises. Ponderamos que a temática não é nova, não obstante esta pesquisa sugere que as discussões e reflexões acerca do tema ainda são prioritariamente abordadas por meio de expectativas biologicistas e ligadas à visão biomédica de forma genérica. Consideramos, também, que os profissionais da educação devem ter embasamento científico acerca da temática, que tenham disponíveis textos, livros que apresentem enfoques que provoquem discussões para que possam trabalhar de modo apropriado, integrando em seu exercício diário as reflexões sobre as questões de gênero, por meio de leituras críticas, desenvolvendo trabalhos que abordem as sexualidades e orientações sexuais e debatendo sobre textos sexistas e preconceituosos.

\section{REFERÊNCIAS}

ANDRADE, F. L. Determinismo biológico e questões de gênero no contexto do Ensino de Biologia: representações e práticas de docentes do Ensino Médio. 2011. Dissertação (Mestrado em Ensino, Filosofia e História das Ciências) - Universidade Federal da Bahia - Ufba, Salvador, BA, 2011.

BARDIN, L. Análise de conteúdo. Lisboa: Edições 70, 1977.

BATISTA, C. A. Educação e sexualidade: um diálogo com educadores. São Paulo: Ícone, 2008.

BORRILLO, D. Homofobia: história e crítica de um preconceito. Trad. Guilherme João de Freitas Teixeira. Belo Horizonte: Autêntica Editora, 2010.

BORTOLINI, A. Diversidade sexual e de gênero na escola. Revista Espaço Acadêmico, n. 123, p. 27-37, 2011. Disponível em: http://diversidade.pr5.ufrj.br/images/BORTOLINI_-_Diversidade_Sexual_e_de_G\%C3\%AAnero_na_Escola_-_Rev._Espa\%C3\%A7o_Acad\%C3\%AAmico.pdf. Acesso em: 15 jul. 2019.

BUTLER, J. Problemas de gênero: feminismo e subversão da identidade. Rio de Janeiro: Civilização Brasileira, 2013.

CATONNÉ, J. A sexualidade, ontem e hoje. São Paulo: Cortez, 2001.

CAVALEIRO, M. C. Escola e sexualidades: alguns apontamentos para reflexões. In: FIGUEIRÓ, M. N. D. (org.). Educação sexual: em busca de mudanças, Londrina: UEL, 2009. p. 153-170.

DINIS, N. F.; CAVALCANTI, R. F. Discursos sobre homossexualidade e gênero na formação em pedagogia. ProPosições, v. 19, n. 2, p. 99-109, 2008.

FELIPE, J.; BELLO, A. T. Construção de comportamentos homofóbicos no cotidiano da educação infantil. In: JUNQUEIRA, R. D. (org.). Diversidade sexual na educação: problematizações sobre a homofobia nas escolas. Brasília: Ministério da Educação; Secretaria de Educação Continuada, Alfabetização e Diversidade; Unesco, 2009. p. 141-158.

FIGUEIRÓ, M. N. D. Sexualidade e afetividade: implicações no processo de formação do educando. In: FIGUEIRÓ M. N. D. (org.). Educação sexual: em busca de mudanças. Londrina, PR: UEL, 2009. p. 187-208. GONSALVES, E. P. Conversas sobre iniciação à pesquisa científica. Campinas, SP: Alínea, 2001.

GOTTARDI, M. L. EAD como modalidade facilitadora para capacitação, formação, qualificação e desenvolvimento de competências profissionais. In: CONGRESSO INTERNACIONAL ABED DE EDUCAÇÃO A DISTÂNCIA - CIAED, 21., 2015. Bento Gonçalves. Anais [...]. Bento Gonçalves, 2015. p. 1-10. Disponível em: http://www.abed.org.br/congresso2015/anais/pdf/BD_110.pdf. Acesso em: 7 ago. 2019.

GUERRA, M. G. R. M.; ROCHA, F. L. Do abandono afetivo em razão da orientação sexual: do exercício de uma paternidade irresponsável. In: ENCONTRO NACIONAL DO CONPEDI/UNICURITIBA, 22., 2013, Curitiba. Anais [...]. Curitiba, 2013. p. 1-23. Disponível em: http://www.publicadireito.com.br/artigos/?cod=273f5064dc00c682. Acesso em: 12 jun. 2019. 
JUNQUEIRA, R. D. Ideologia de gênero: a gênese de uma categoria política reacionária - ou: A promoção dos direitos humanos se tornou uma "ameaça à família natural"? In: RIBEIRO, P. R. C.; MAGALHÃES, J. C. (org.). Debates contemporâneos sobre educação para a sexualidade. Rio Grande, RS: Furg, 2017. p. 25-52. LOBO, A. R. Educação a distância: a menor distância entre o sonho e a realidade. Anuário da Produção Acadêmica Docente, v. 5, n. 11, p. 107-115, 2011.

LOURO, G. L. Gênero, sexualidade e educação: uma perspectiva pós-estruturalista. Petrópolis: Vozes, 2013.

LOURO, G. L. Educação e docência: diversidade, gênero e sexualidade. Revista Brasileira de Pesquisa sobre Formação Docente, v. 3, n. 4, p. 62-70, 2011.

MAISTRO, V. I. A. Desafios para a elaboração de projetos de educação sexual na escola. In: FIGUEIRÓ, M. N. D. (org.). Educação sexual: em busca de mudanças. Londrina, PR: UEL, 2009. p. 35-62.

MELO, S. M. M. Corporeidade e diversidade: conversando sobre a delicada trama entre o eu e o outro. In: FIGUEIRÓ, M. N. D. (org.). Educação sexual: múltiplos temas, compromisso comum. Londrina: UEL, 2009. p. 113-128.

MINAYO, M. C. S. (org.). Pesquisa social. Teoria, método e criatividade. 21. ed. Petrópolis: Vozes, 2002.

MOKWA, V. M. N. F.; GONINI, F. A. C.; RIBEIRO, P. R. M. A possível ausência do conceito de gênero na visão de professoras de ensino fundamental. Revista Ibero-Americana de Estudos em Educação, v. 4, n. 3, p. 1-12, 2009.

MOREIRA, L. Intolerância e homofobia: a construção da cidadania pela instituição educacional no Brasil. Revista Eletrônica Pro-Docência. Londrina, PR: UEL, v. 1, n. 1, p. 1-23, 2012.

RIZZA, J. L.; RIBEIRO, P. R. C.; MOTA, M. R. A. A sexualidade nos cursos de licenciatura e a interface com políticas de formação de professores/as. Educação e Pesquisa, v. 44, p. 1-18, 2018. Disponível em: http://www. scielo.br/scielo.php?script=sci_abstract\&pid=S1517-97022018000100316\&lng=en\&nrm=iso\&tlng=pt. Acesso em: 16 maio 2019.

RODRIGUES, A. R. F.; SALLES, G. D. Educação sexual, gênero e diversidade sexual: formação de professoras e alunas multiplicadoras como metodologia de ensino. In: SIMPÓSIO GÊNERO E POLÍTICAS PÚBLICAS, 2., 2011, Londrina. Anais [...] Londrina, 2011. p. 1-13. Disponível em: http://www.uel.br/eventos/gpp/pages/ arquivos/Adriana.pdf. Acesso em: 14 maio 2019.

SANTOS, A. E. C. Espaço escolar, homossexualidades e prática discursiva. 2015. Dissertação (Mestrado em Gestão do Território) - Universidade Estadual de Ponta Grossa - UEPG, Programa de Pós-Graduação em Geografia, Ponta Grossa, PR, 2015.

SCOTT, J. W. Gênero: uma categoria útil de análise histórica. Educação e Realidade, v. 20, n. 2, p. 71-99, 1995.

VARELA, C. M.; RIBEIRO, P. R. C. Educação para a sexualidade: a constituição de um campo conceitual. In: RIBEIRO, P. R. C.; MAGALHÃES, J. C. (org.). Debates contemporâneos sobre educação para a sexualidade. Rio Grande, RS: Furg, 2017. p. 11-24. 